\title{
Absorbable Barbed Threads for Lower Facial Soft- Tissue Repositioning in Asians
}

\author{
Rungsima Wanitphakdeedecha (D) - Chadakan Yan - Janice Natasha C. Ng • \\ Salvatore Fundarò
}

Received: April 13, 2021 / Accepted: June 16, 2021 / Published online: July 3, 2021

(C) The Author(s) 2021

\section{ABSTRACT}

Introduction: Asian patients often seek to address lower facial aging through clinical interventions that increase anterior projection and jawline contouring. The Definisse ${ }^{\mathrm{TM}}$ (also known as Happy Lift $^{\mathrm{TM}}$ ) thread lift treatment uses barbed absorbable threads to suspend tissues and induce biostimulation. We evaluated the efficacy and safety of absorbable barbed threads for lower facial reshaping in Thai patients.

Methods: This prospective, evaluator-blinded study enrolled 27 Thai patients diagnosed with mild to moderate facial laxity. Patients underwent thread implantation along the mandibular angle with one of two double needle thread lengths $(12$ and $23 \mathrm{~cm})$ to create a "J stitch". Primary outcome was the clinical improvement in facial laxity as graded by two blinded dermatologists at baseline, immediately after treatment, and at 1 week and 1, 2, 3, 6, and 12 months follow-up. Objective measurements included volume in the jawline, nasolabial folds, and submental area. Patients' self-

R. Wanitphakdeedecha $(\bowtie) \cdot$ C. Yan · J. N. C. Ng Department of Dermatology, Faculty of Medicine Siriraj Hospital, Mahidol University, Bangkok, Thailand

e-mail: rungsima.wan@mahidol.ac.th

S. Fundarò

Multimed Day Surgery Hospital, Bologna, Italy assessment scores and adverse reactions were recorded.

Results: Of the 27 patients recruited to the study, 25 (92.6\%) attended all follow-up visits. Clinical improvement of facial laxity was observed immediately after thread implantation. There was significant volume improvement in the jawline, nasolabial folds and submental area at almost all follow-up visits $(p<0.007)$, with most patients $(51.9 \%)$ reporting excellent lifting effect as early as the 1 week follow-up visit. All adverse reactions were mild and resolved spontaneously without any medical intervention.

Conclusion: Implantation of absorbable barbed threads is a safe and effective treatment for facial rejuvenation in Thai patients. Long threads $(23 \mathrm{~cm})$ showed a slight superiority to short threads $(12 \mathrm{~cm})$ in terms of face-lifting efficacy, which suggests the benefit of additional barbs in tissue suspension and biostimulation. The disadvantage of absorbable threads is that their visible lifting effects are not as longlasting as those of non-absorbable ones, since they are reabsorbed from 6 months onwards.

Trial registration: ClinicalTrials.gov identifier: TCTR20210415001. This clinical trial was retrospectively registered 12 April 2021.

Keywords: Absorbable barbed threads; Lower face lifting facial rejuvenation 


\section{Key Summary Points}

\section{Why carry out this study?}

Asian patients often seek to address lower facial aging through clinical interventions that increase anterior projection and jawline contouring.

Implantation of absorbable barbed threads is a safe and effective treatment for facial rejuvenation.

\section{What was learned from this study?}

Long threads $(23 \mathrm{~cm})$ showed a slightly better efficacy than short threads $(12 \mathrm{~cm})$ in terms of face lifting.

Additional barbed threads may benefit tissue suspension and biostimulation.

Lifting effects of absorbable threads are less long-lasting than those of nonabsorbable threads.

\section{INTRODUCTION}

Facial aging is a three-dimensional change that involves all facial tissues: bone, ligaments, muscles, and fatty tissue $[1,2]$. Bony resorption in the maxilla and zygoma causes loss of maxillary angle and projection [3-5]. Bone is also resorbed in the mandible, which then recedes anteriorly, reducing tissue tone of the lower facial tissue but increasing laxity of the retaining ligament [6]. Aging and the force of gravity cause a degree of laxity in the ligamentous support, resulting in soft tissue descent. However, it is important to establish whether the aesthetic appearance of soft tissue descent is due to a true ligament laxity or to a perceived laxity of overhanging but deflated tissue originating above these ligaments [7]. More controversial is the age-related modification of facial muscles. Using magnetic resonance imaging (MRI), Le Louarne [8] showed that the youthful face has a curvilinear contour created by facial mimetic muscles presenting an anterior surface convexity. This convexity results from underlying fat pads positioned deep in the muscles. Repetitive muscular contractions and the reduction of deep fat volume during aging gradually straighten and shorten the facial mimetic muscles. Interestingly, MRI studies [9] on midface aging failed to detect significant differences in the length, thickness, or volume of mimetic muscle between young and old subjects, or in fatty infiltration of muscles between the age groups. Age-related fatty tissue changes vary depending on the affected facial area and depth of the fat compartment. Facial aging is associated with the loss of soft tissue fullness (including the malar, mandibular, mental, and perioral sites) combined with hypertrophic or persistent superficial fat in the submentum, labiomental crease, and lateral nasolabial fold, jowl, and malar fat pad regions [2, 9-12]. Agerelated signs manifest most significantly in the lower face as jowls [13, 14]. The age-related modification of facial fat compartments and of the superficial musculo-aponeurotic system (SMAS) are caused by the relaxation and elongation of retaining ligaments and the retinacula cutis, volume reduction of fat compartments (mainly deep fat compartments), and downward migration and hypertrophy of superficial facial fat $[15,16]$.

SMAS rhytidectomy is the gold standard treatment for moderate to severe skin laxity, but because of its complications, most patients seek nonsurgical procedures to achieve facial reshaping [17]. Advances in skin laxity treatments have led to less invasive procedures, such as thread lifting, which was approved by the US Food and Drug Administration in 2004 [18]. Early thread lifts employed nonabsorbable barbed sutures to raise the skin during minimally invasive outpatient procedures with shorter recovery periods or downtime. However, these procedures produced serious complications that ultimately led to the development of absorbable sutures [19].

While nonabsorbable threads are made of polypropylene and persist indefinitely in the subdermis, absorbable threads are made from materials such as polydioxanone (PDO), poly-Llactic acid (PLLA), polyglycolic acid, or poly-L- 
lactic acid and caprolactone that can undergo enzymatic hydrolysis [20, 21]. Absorbable threads can be smooth or barbed, with the former indicated for reshaping and the latter for tissue suspension [22]. Threads developed for aesthetic facial procedures include free-floating bidirectionally barbed sutures, unidirectional barbed sutures, and anchored bidirectional double-threaded sutures [23]. Bidirectional barb thread systems create an antagonistic traction between the barbs in two opposing directions. Over time, a tissue-suture interaction occurs; this becomes biostimulatory and ultimately influences aesthetic outcomes [24].

The subdermally implanted Definisse ${ }^{\mathrm{TM}}$ (also known as Happy $\mathrm{Lift}^{\mathrm{TM}}$ in some countries) thread lift treatment is a double-needle, absorbable, monofilament, suspension, barbed thread composed of synthetic poly-L-lactic acid and caprolactone [p(LA-CL)] polymers [25]. The biostimulatory action of the thread induces fibrosis and facilitates tissue suspension, which in turn leads to a lifting effect for at least 12 months before the thread is completely resorbed in the body [23]. Upon resorption, the fully biodegradable and soluble thread polymers hydrolyze into low-molecular-weight molecules, which induce collagen and hyaluronic acid production [23]. Definisse ${ }^{\mathrm{TM}}$ received a Conformité Européenne marking in 2015, and preliminary studies reported excellent outcomes with minimal complications $[20,26]$.

Nowadays, Asians with lower facial laxity often seek clinical interventions to increase anterior projection and jawline contouring [18]. Our objective was to evaluate the efficacy and safety of the Definisse ${ }^{\mathrm{TM}}$ absorbable barbed threads for lower facial lifting in Thai patients.

\section{METHODS}

This was a prospective, single-center, and evaluator-blinded study. Twenty-seven Thai patients, both male and female, aged between 30 and 55 years, with a maximum body mass index of $30 \mathrm{~kg} / \mathrm{m}^{2}$ and mild to moderate facial laxity (1.5-2.5 points, according to a 4-point Quantitative Grading Scale for laxity) [27] were included. Patients were excluded if they: (1) were pregnant or lactating; (2) had a history of keloid or hypertrophic scar formation, of botulinum toxin, mesotherapy, or laser treatment in the last 6 months, or had a histroy of filler injection in the last 12 months; (3) had concurrent dermatological disease, autoimmune disease or infection in the targeted area; or (4) were currently using medications, including antibiotics, anticoagulants, vitamin $\mathrm{C}$ or $\mathrm{E}$ supplementation, steroids, or nonsteroidal anti-inflammatory drugs Other exclusion criteria were a history of allergy to p(LA-CL), local anesthesia, or adrenaline; a history of smoking; and signs of non-cooperation or non-compliance with medical treatment requirements.

All patients underwent one session of thread implantation for lower facial laxity using either short $(12 \mathrm{~cm})$ or long $(23 \mathrm{~cm})$ absorbable barbed threads, which differ based on the lengths of their barbed sections bound by two straight, cut-edge needles of $10 \mathrm{~cm}$, respectively [29] (Definisse $^{\mathrm{TM}}$; RELIFE, Menarini Group, Florence, Italy). The absorbable thread presents barbs only within its intermediate areas and is smooth at its ends and midsections [29].

Barbed threads allow the creation of a "J stitch" during implantation to reinforce the device's anchoring and support capacity. The J stitch is performed by reintroducing the needle into the needle exit hole and rotating it at a $20^{\circ}-30^{\circ}$ angle with respect to the inserted thread. The needle is inserted to a depth of $2 \mathrm{~cm}$ and is then removed by pulling it out completely through the skin. Extracting the needle in this way also completely pulls the thread out along with it, allowing it to penetrate the skin. The acute angle between the two tracts of thread and the opposing orientations of the barbs (Fig. 1a) increase considerably the thread's holding force and resistance to slipping and compresses the tissues between the angles. Generally, when an angle is created with a barbed suture, the holding strength of the thread increases at that specific point [30].

All patients were treated with the following jawline reshaping procedure. The length of barbed section was selected according to the patient's facial dimensions. If the distance between the entry and exit points exceeded 7 $\mathrm{cm}$, the $23-\mathrm{cm}$ thread was chosen. The goal of 


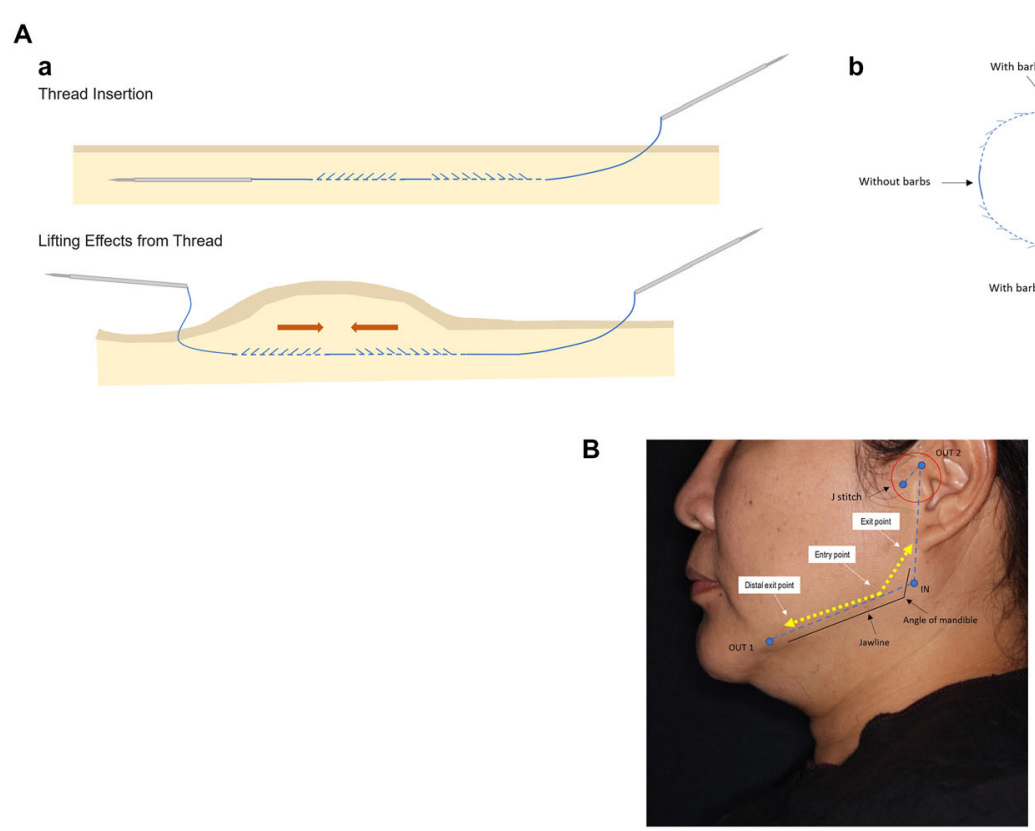

Fig. 1 a, b Schematic of the "J stitch" thread implantation using a bidirectional barbed thread with its smooth and barbed parts and needles (a) and the entry and exit points of "J stitch" thread implantation (b)

thread placement was to reposition the lower face fat compartments, specifically the inferior jowl fat, middle cheek fat and lateral cheek fat, and to restore jawline definition. Before implantation, the entry and exit points were marked with a line starting at the level of the ear at the infra-auricular region, between the ear lobe and the posterior border of the platysma muscle, posterior to the mandibular angle. One exit point was marked at the medial border of the jowl defect and lateral to the marionette line; a second exit point was marked inferior to the sideburn. The line was extended to the mandible angle and along the jawline toward the midface and then superiorly to a midpoint between the chin and lip, before returning to the starting point (Fig. 1b). The reshaping lines that join the entry and exit points mark the path that the thread would traverse when pulled through the skin.

Preoperatively, $1 \%$ lidocaine with adrenaline was injected through the entry and exit points. The entry points were created by inserting an $18 \mathrm{G}$ needle perpendicularly into the skin and approximately $5 \mathrm{~mm}$ into the subcutaneous tissue, with an exit point created approximately 4-6 cm distant the entry site. The thread was then inserted along the mandibular angle and the tails of the suture along the length of the mandibular ramus before subsequently exiting 4-6 cm distant. To ensure that the barbs of the thread were properly situated within the soft tissue, the device was pulled taut at both the entry and exit points. Post-procedure, fusidic acid ointment was applied to the area twice a day for 1 week. Patients were advised to wash and dry the treated area gently without exerting force, and if applying makeup to the treated area, to do so gently. They were also advised to avoid high-impact sports for 7 days and to avoid dental procedures, visiting saunas, or applying massage and heat to the treated area for at least 1 month.

The primary outcome of the study was a clinical improvement in the grade of lower face and jawline laxity and soft tissue ptosis using a 6-point scale: worse, no lifting effect (no change), mild lifting effect (1-25\%), moderate lifting effect (26-50\%), marked lifting effect (51-75\%), and excellent lifting effect (76-100\%). An improvement of 100\% indicates the absence of skin laxity while no improvement $(0 \%)$ indicates no change between preand post-treatment states. Photographs were 
subjectively evaluated by two blinded dermatologists at baseline, immediately after the treatment, and at 1 week and 1, 2, 3, 6, and 12 months follow-up. All clinical photographs were taken with identical camera settings, lighting, and positioning using a Canon PowerShot G9 stand-off camera (OMNIA Imaging System, Canfield Scientific Inc., Fairfield, NJ).

In addition, facial volume in the jawline, nasolabial folds, and submental area were objectively evaluated using three-dimensional photographs captured by the Vectra H1 Imaging System ${ }^{\circledR}$ (Canfield Scientific Inc.). Patients also performed self-assessments using the same 6-point scale as described above at their followup visits (1 week and 1, 2, 3, 6 and 12 months after treatment). At every follow-up visit, pain was rated from 1 to 10 using a visual analog scale. Any adverse reactions, including bleeding, edema, bruising, and dimple formation, were also evaluated, as per the study protocol.

Descriptive analysis was used for the demographic data. Volume changes in the facial areas were calculated using the one-sample $t$-test, and the adjusted $p$ value of $<0.007$ was considered statistically significant. Statistical analyses were performed using SPSS Statistics for Windows, version 18.0 (SPSS/IBM Corp., Armonk, NY, USA).

This study was approved by the ethics committee of the Siriraj Institutional Review Board (Certificate of Approval Number: si293/2017). Written informed consent was obtained for the publication and use of all patients' images prior to their enrollment in the study. This study was performed in accordance with the Helsinki Declaration of 1964 and its subsequent amendments.

\section{RESULTS}

Among the 27 patients recruited to the study, 25 (92.6\%) completed the follow-up visits; two patients were unable to attend the 12-month follow-up visit and were excluded from the final analyses. The demographic data of the 25 patients included in the analysis are given in Table 1.
Table 1 Demographic data of the 25 patients included in the analysis

\begin{tabular}{ll}
\hline Demographic characteristics & Values $(\boldsymbol{n}=\mathbf{2 5})^{\mathbf{a}}$ \\
\hline Sex & $1(4)$ \\
Male & $24(96)$ \\
Female & $44.3 \pm 9.26$ \\
Age (years), mean \pm SD & \\
Skin laxity & $18(72)$ \\
Mild skin laxity & $7(28)$ \\
Moderate skin laxity & \\
Length of threads used & $16(64)$ \\
Short $(12 \mathrm{~cm})$ & $9(36)$ \\
Long $(23 \mathrm{~cm})$ &
\end{tabular}

$S D$ Standard deviation

${ }^{\text {a }}$ Values are presented as a number with the percentage in parentheses except where indicated otherwise

The subjective evaluation of laxity of the lower face using the 6-point scale is shown in Fig. 2. Immediately after implantation, $32 \%$ of patients showed a mild lifting effect relative to the baseline. At 1 week and 1, 2, and 3 months follow-up, the majority of patients exhibited a mild lifting effect relative to baseline $(40,48$, 56 , and 40\% respectively). However, at 6 and 12 months follow-up, most patients (40 and 56\%, respectively) showed no lifting effect when compared to the baseline. The clinical improvement of lower facial laxity after implantation of 23-cm (long) and 12-cm (short) absorbable barbed threads is presented in Figs. 3 and 4.

Quantitative assessment of the jawline demonstrated a marked increase in the volume difference that occurred immediately after treatment (Fig. 5a). Over the 12-month followup period, the effect was stable and statistically significant when compared to the baseline state. Subgroup analysis suggested that even if the longer threads seemed to have a greater initial effect on volume than the short threads, both had a similar and stable efficacy after 2 months and up to 12 months (Fig. 5b). Although the 


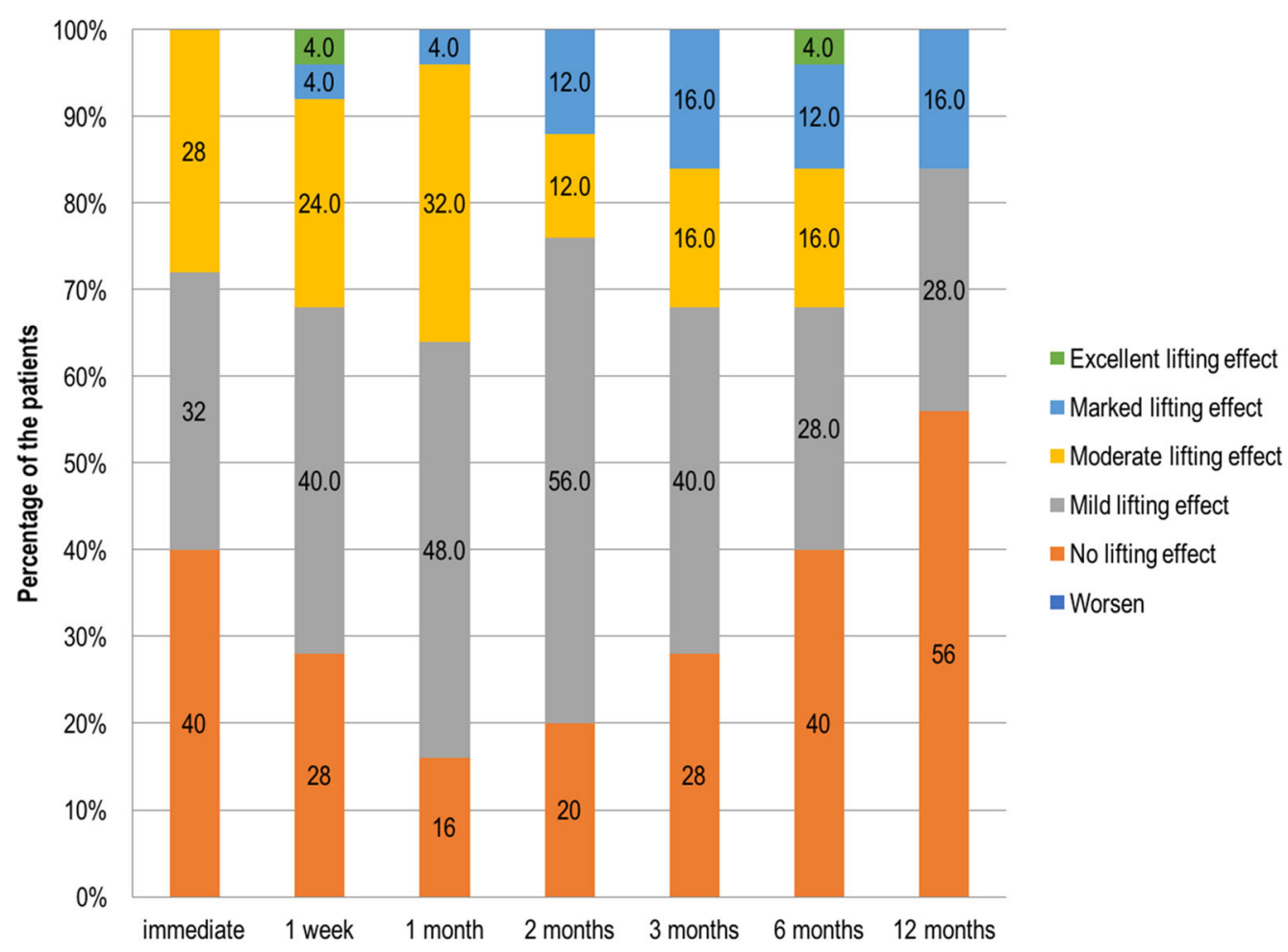

Fig. 2 Subjective evaluation of lower facial laxity by comparative evaluation of photographs at baseline and at all follow-up visits. $t x$ Treatment

jawline reshaping technique used in this study targeted the lower face, quantitative assessments also indicated a positive and immediate effect on the nasolabial fold area (Fig. 6a) and submental volumes (Fig. 6b). At 1 month postprocedure, the initial spikes had decreased, and in the submental area the volume had stabilized to a higher than baseline level. Subgroup analyses also demonstrated that long threads produced a numerically higher difference in submental volume across the study period compared to short threads (Fig. 6c).

Patient self-assessments were also recorded at all follow-ups (Fig. 7). From as early as 1 week after treatment, the majority (51.9\%) of patients reported excellent lifting effects. The scores declined at successive follow-ups, but while many patients $(48.1 \%)$ reported a marked lifting effect at 1 month follow-up, $60.9 \%$ of patients had a moderate lifting effect at 2 months follow-up. At 3 months follow-up, most patients $(53.8 \%)$ reported a marked lifting effect, while at 6 months follow-up, $32 \%$ of patients reported a moderate lifting effect. A minority (28\%) of patients reported no lifting effects at 12 months follow-up.

Adverse reactions to the thread implantation procedure are presented in Table 2 . All patients had a mean pain score of $3.91 \pm 1.79$ (scale $0-10)$, which lasted for an average duration of $3.15 \pm 2.27$ days. We considered this to be reasonable for thread procedures and not warranting clinical intervention. Some patients developed edema (33.3\%), bruising (81.48\%), dimple formation $(22.22 \%)$, and palpable nodules (11.1\%). All adverse reactions were mild and resolved spontaneously without any medical intervention.

\section{DISCUSSION}

With aging, the facial anatomy undergoes changes characterized by volume loss, deepening of the nasolabial folds and marionette lines, and significant jowl formation [17]. Barbed 

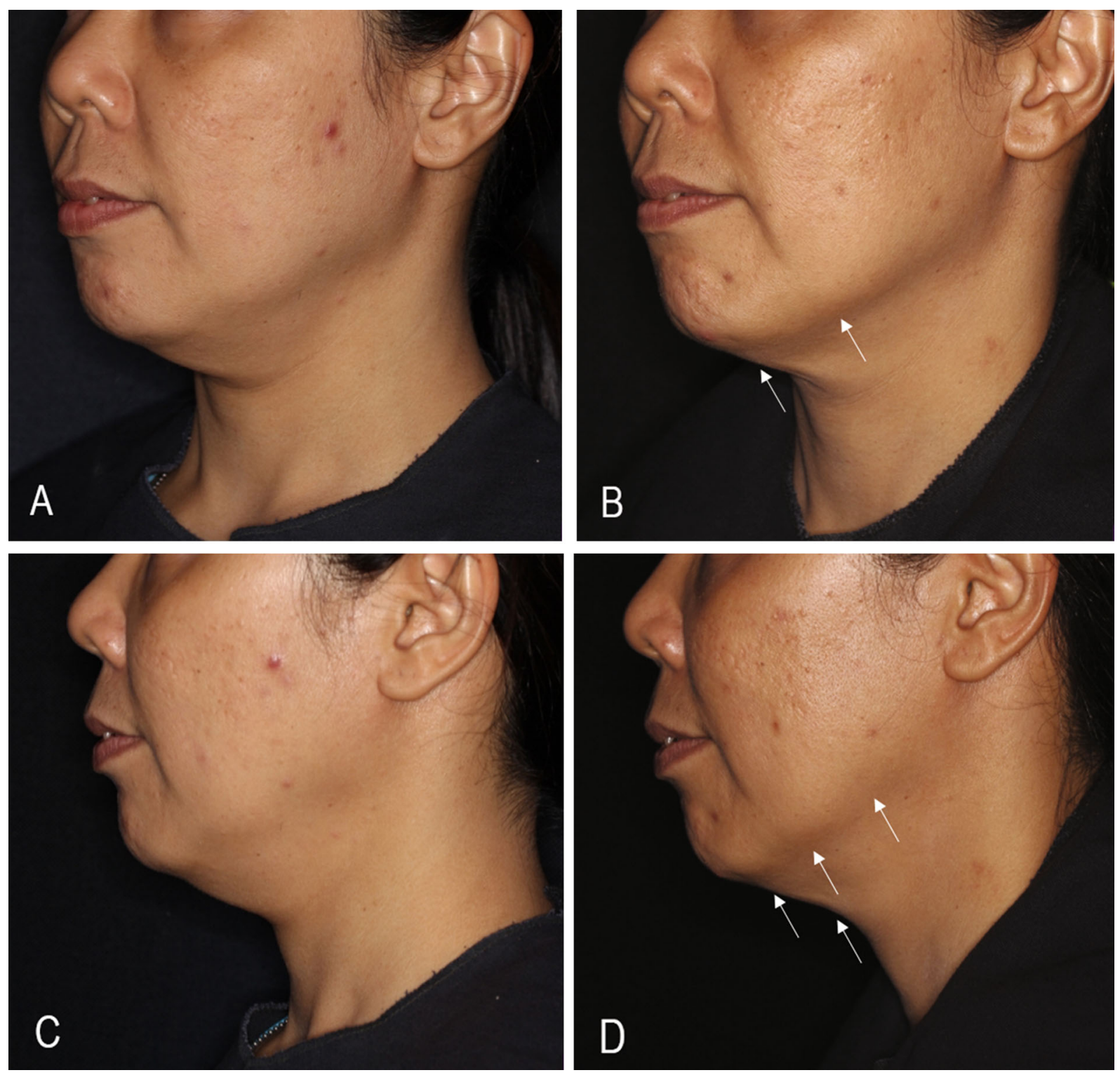

Fig. 3 Clinical improvement in lower facial laxity after implantation of long absorbable barbed threads from baseline (a, c) to 12 months of follow-up $(\mathbf{b}, \mathbf{d})$

suspension threads target specific facial areas to produce a lifting effect (or volume repositioning) for recontouring, with the potential benefit of improved skin quality due to the induction of neocollagenesis [20].

In our study, a mild lifting effect was noted immediately after implantation when compared to baseline. The immediate lifting effect was probably due to the mechanical tissue suspension that occurred after the implantation. Most of the patients maintained this lifting effect until 6 months post-procedure, which gradually diminished over time. We expected this diminishing effect to occur and believe it reflects thread resorption kinetics [31]. Our experience is that $\mathrm{p}(\mathrm{LA}-\mathrm{CL})$ threads also resorb at a similar rate to PDO threads (at 6 months) although further study is warranted. We do not believe this outcome to be related to patient ethnicity. Some patients were able to maintain the lifting effect up to the 12 month follow-up visit even though $56 \%$ of patients presented 

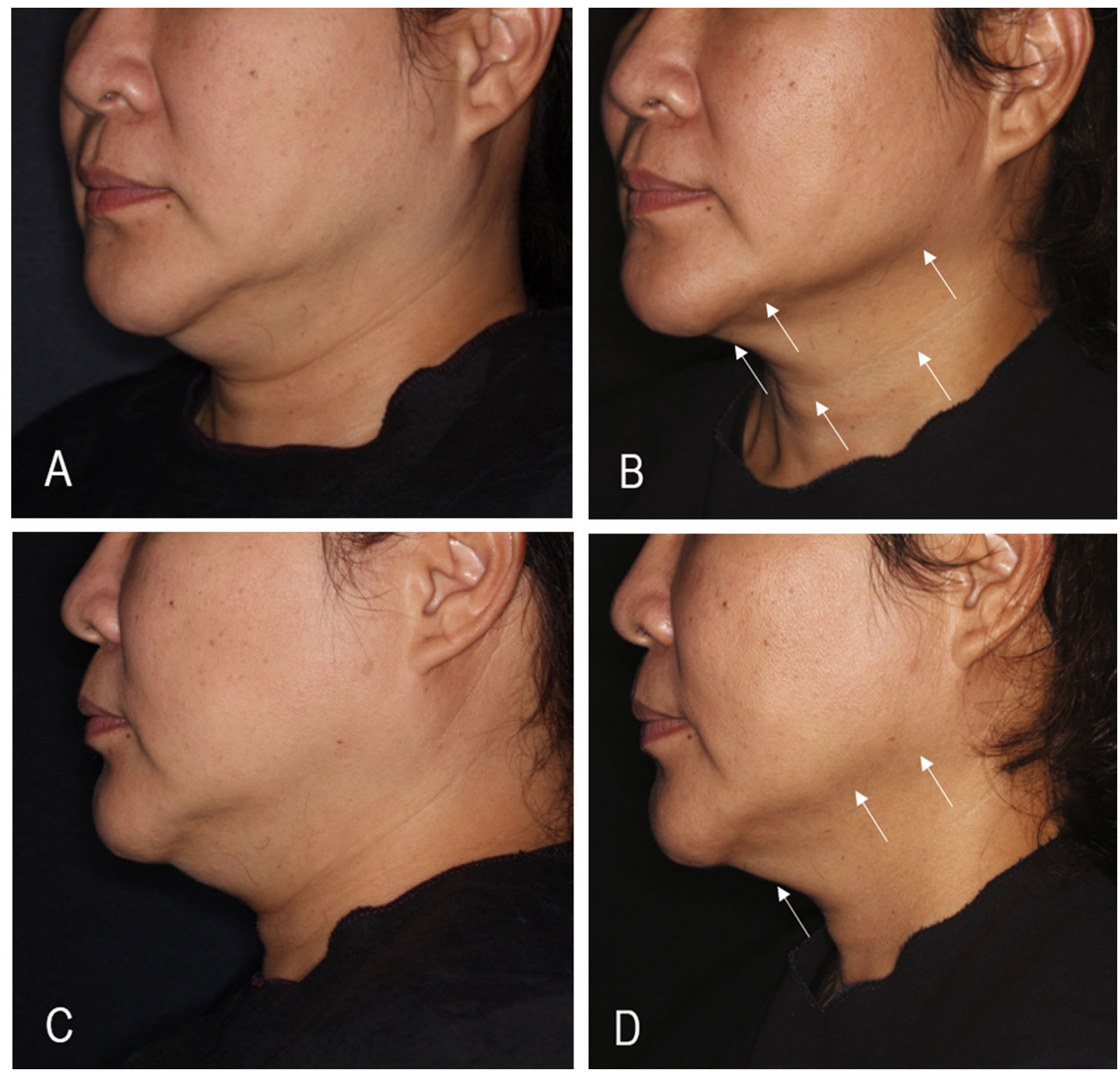

Fig. 4 Clinical improvement on lower facial laxity after implantation of short absorbable barbed threads from baseline (a, c) to 12 months of follow-up $(\mathbf{b}, \mathbf{d})$

with no lifting effect. Thread resorption most likely occurred between 8 and 12 months postprocedure. Based on previous studies and the thread's composition, neocollagenesis was most likely initiated at 1 month post-implantation $[18,23,26,28]$.

Our subgroup analysis of $23-$ and $12-\mathrm{cm}$ threads in different treatment areas revealed that both thread lengths were associated with significant volume differences at nearly all follow-up timepoints relative to the baseline $(p<0.007)$. Mechanical lifting effects were better with the $23-\mathrm{cm}$ threads, likely due to the presence of more barbs that improved tissue anchoring and jawline contouring. The greater lifting effect may also have been facilitated by positioning the exit point of the $23-\mathrm{cm}$ thread at a lower and more anterior point on the face than that of the $12-\mathrm{cm}$ thread. This observation indicates that the choice of length of the thread to be used for the procedure must be based on the severity of skin laxity. 


\section{A}

$\rightarrow$ Mean Difference

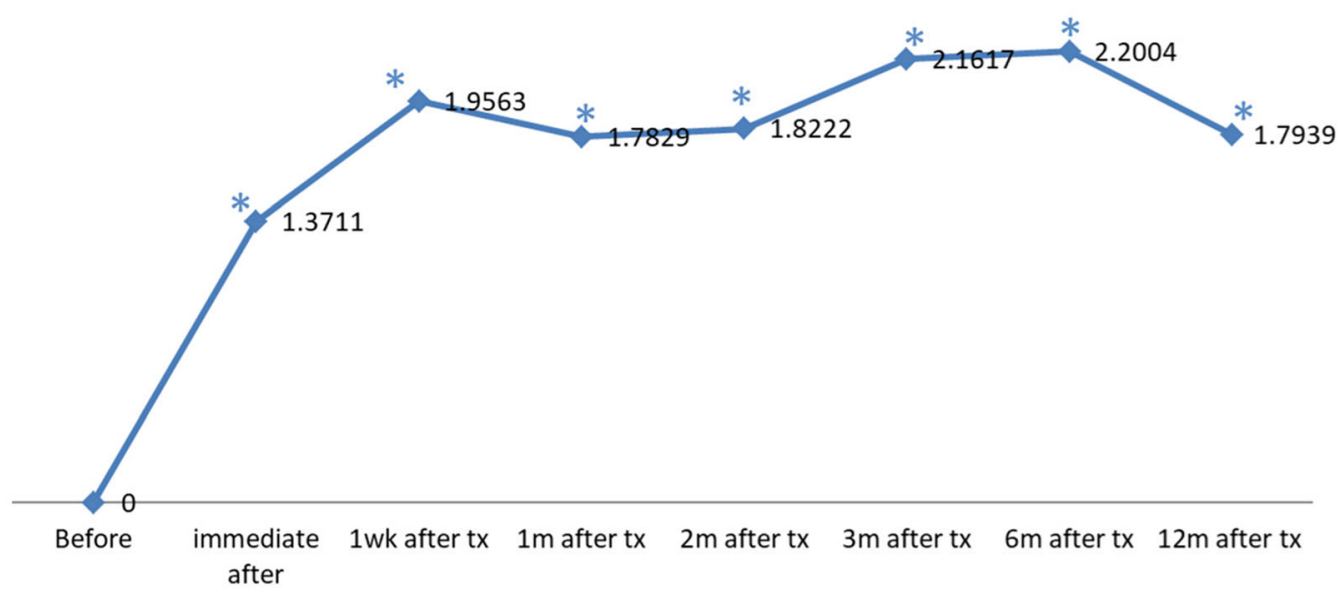

B

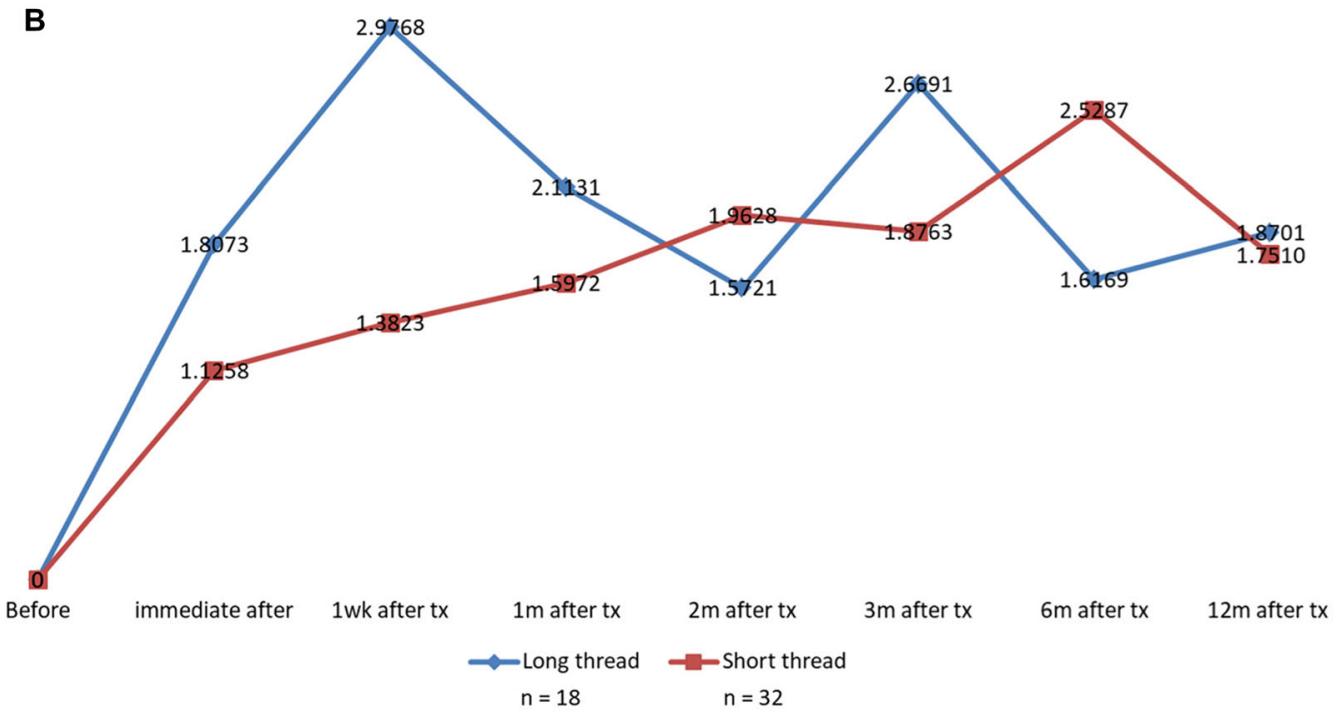

Fig. 5 a Assessment of volume differences in the jawline using Vectra H1 Imaging System ${ }^{\circledR}$ at baseline and all follow-up visits. b Subgroup analysis of volume differences in the jawline with either long or short threads. $w k$ Week, $m$ month

As the treatments were provided free of charge in our study, patients may have overrated their treatment effects; consequently, the assessments of the blinded dermatologists are potentially more reliable. However, we noted that, compared to the physician evaluation scores, our patients' self-assessment scores reflected a better perception of the lifting effect. Patient satisfaction is important in thread lifting, particularly in those with less severe facial laxity, as realistically such patients may only experience an incremental lifting effect rather than a radical one. This was a consideration in our study because the immediate results indicated excellent lifting effects which then stabilized to a marked and moderate lifting effect at subsequent follow-ups. The threads also demonstrated a good safety profile with no severe adverse reactions.

Barbed threads were initially developed to close skin wounds without the need for knots [24]. To treat rhytids and ptotic skin, barbed 
A

$\leadsto$ Mean Difference $n=50$

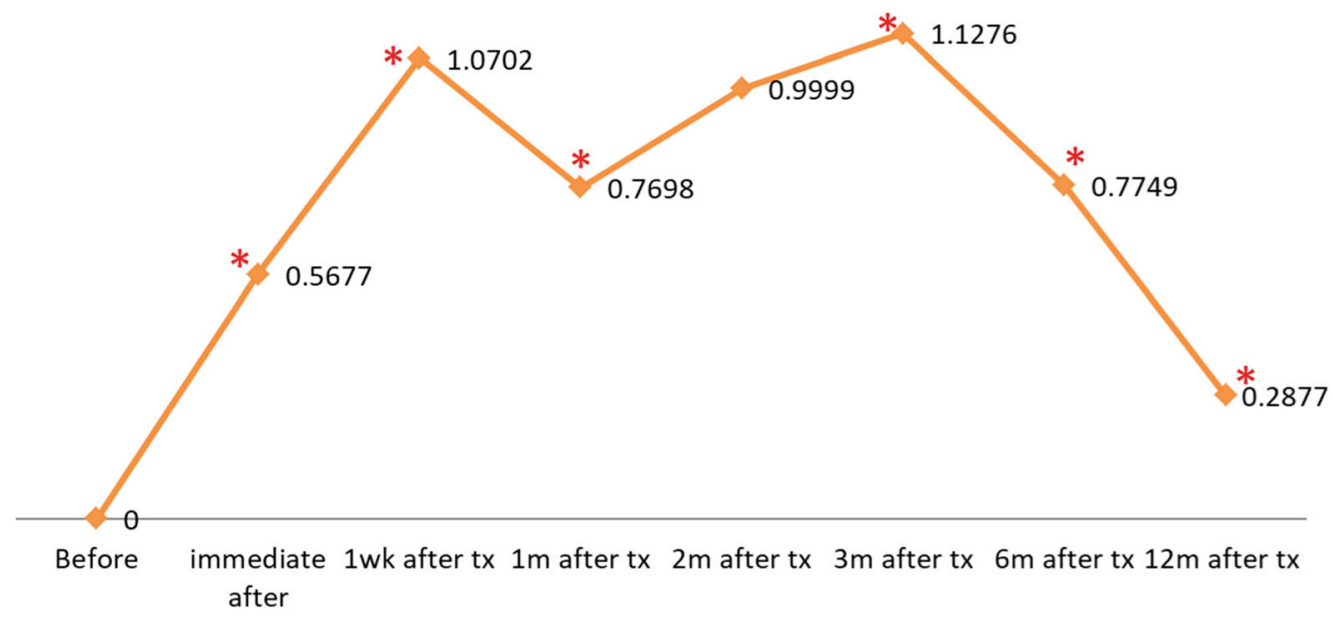

B

$\sim$ Mean Difference $n=25$

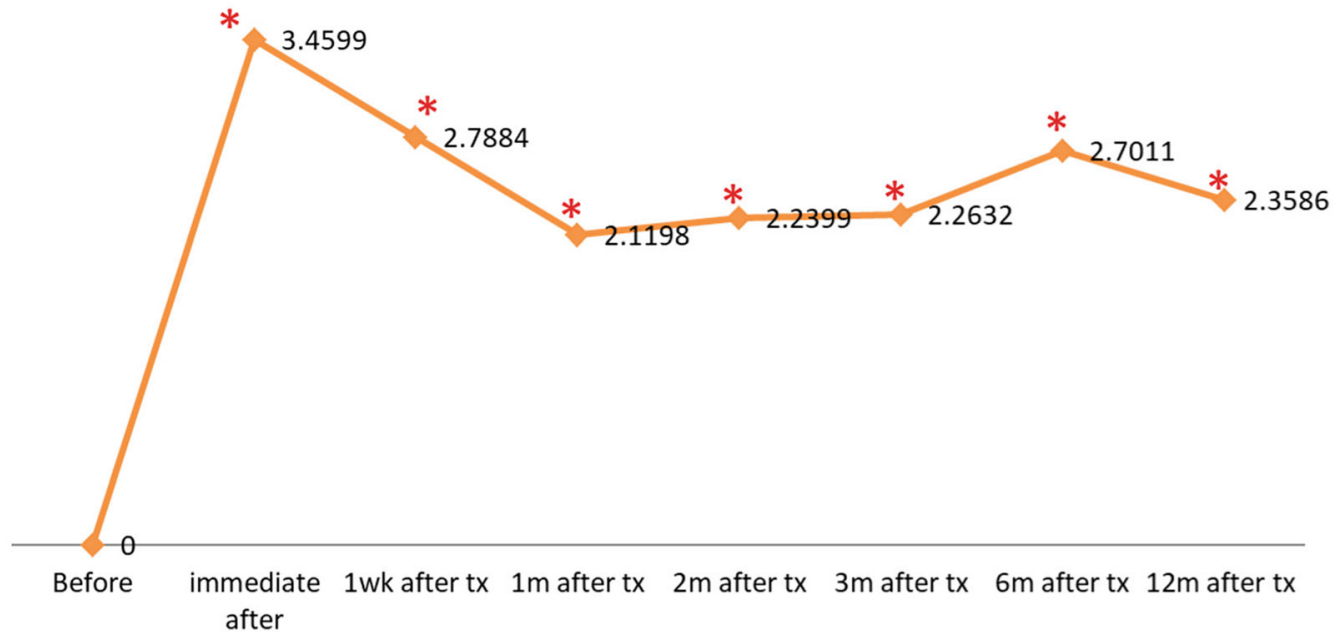

C Long thread

Short thread

$\multimap$ Mean Difference $n=9$

$\leadsto$ Mean Difference $n=16$

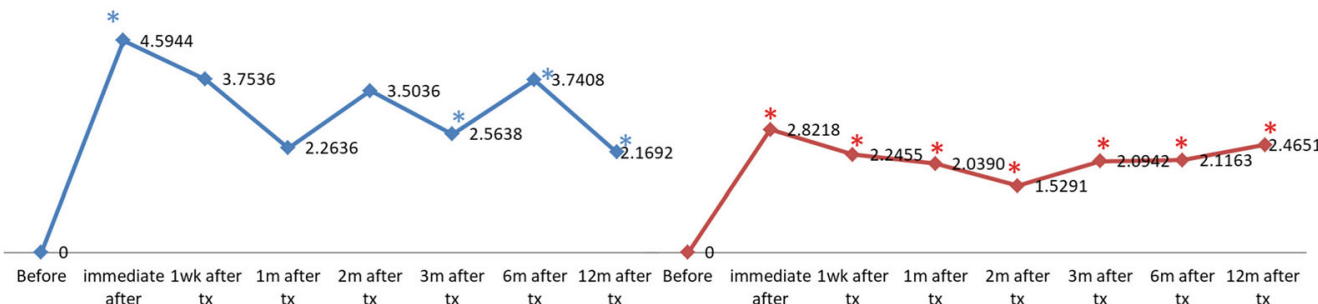

Fig. 6 a, b Assessment of volume differences in the nasolabial fold (a) and in the submentum area (b) using up visits. c Subgroup analysis of volume differences with the Vectra H1 Imaging System ${ }^{\circledR}$ at baseline and all followeither long or short threads 


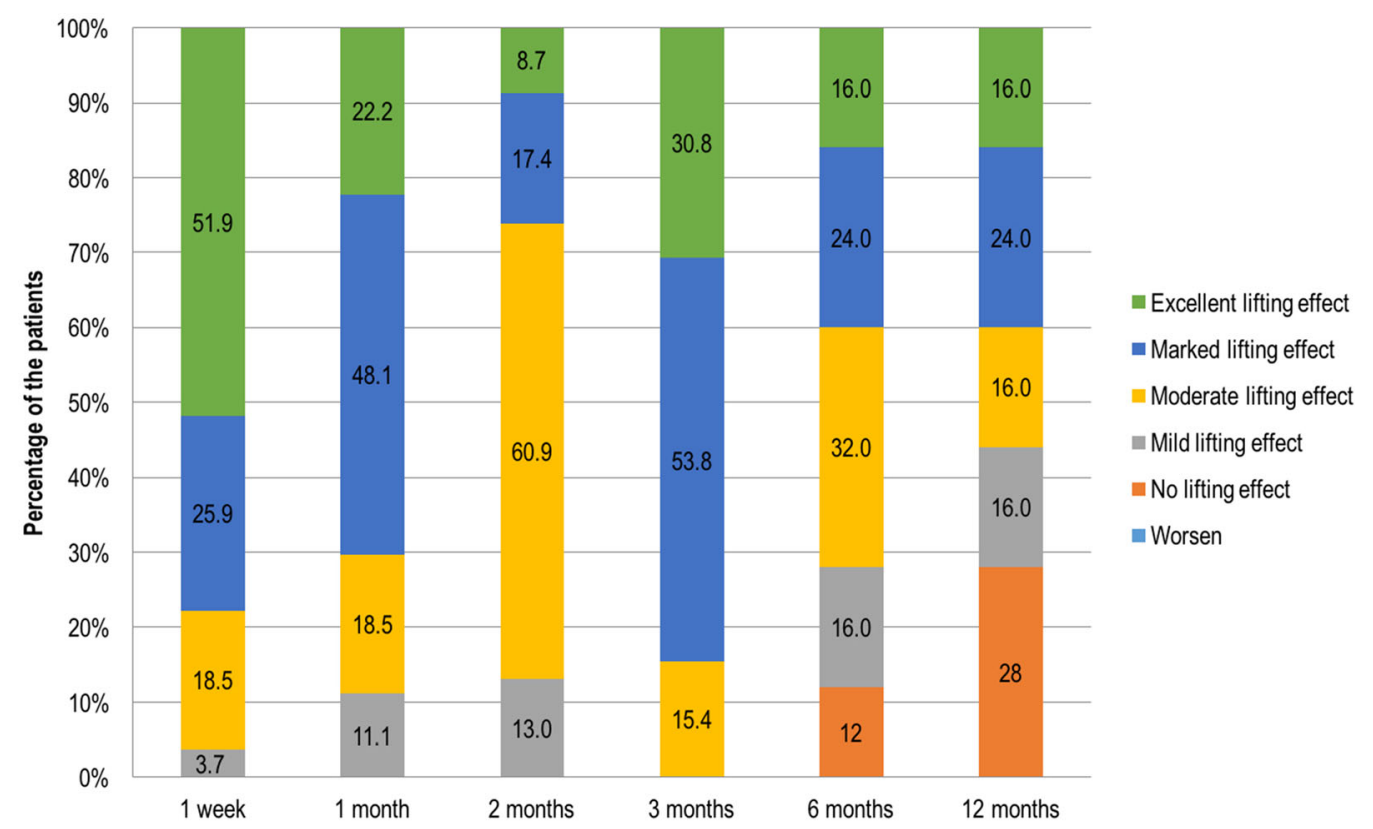

Fig. 7 Patients' self-assessment on the improvement in lower facial laxity at baseline and follow-up visits

Table 2 Adverse reactions to the thread implantation procedure and their duration

\begin{tabular}{lrl}
\hline $\begin{array}{l}\text { Adverse } \\
\text { reaction }\end{array}$ & $\boldsymbol{n}(\%)$ & $\begin{array}{l}\text { Duration (days) } \\
(\text { mean } \pm \text { SD) }\end{array}$ \\
\hline Pain & $25(100)$ & $3.15 \pm 2.27$ \\
Edema & $8(33.3)$ & $4.58 \pm 2.58$ \\
Bruising & $22(81.5)$ & $4.27 \pm 2.82$ \\
Dimple formation & $6(22.2)$ & $6.04 \pm 2.55$ \\
\hline
\end{tabular}

threads were designed to suspend tissues by anchoring them entirely within the subcutaneous layers while minimizing dissections and foreign body reactions, although a fibrous capsule still forms $[17,22,30-32]$. The original APTOS thread (APTOS, Tbilisi, Georgia) was a multi-toothed, non-absorbable (polypropylene) thread with bidirectional barbs [22]. It was later redesigned with unidirectional barbs, but the barb attachment to the tissues still induced an inflammatory response and fibrosis around the threads [22]. Absorbable threads were then developed, including those used in the
Silhouette InstaLift ${ }^{\mathrm{TM}}$ procedure, which are made from biodegradable and biocompatible polyglycolide/L-lactide polymers and contain bidirectional cones made of lactide glycolide [17]. Absorbable monofilament threads can also be manufactured from PDO with barbs in a spiral pattern around the thread surface $[32,33]$. Absorbable polymers are clinically beneficial as they avoid the need for thread removal or knot creation, thus reducing foreign body reactions and, consequently, tissue scarring. PDO threads reabsorb within 6 months and induce fibroblast production of collagen in a defined region, but mainly around the threads and its barbs, to create volume and improve skin elasticity and texture [34]. PLLA threads require more time to be resorbed than PDO threads and thus also prolong collagenesis. PLLA cones facilitate the lifting, shaping, and volumization of sagging facial tissues [34].

In this study, we used Definisse ${ }^{\mathrm{TM}}$ threads, which consist of absorbable p(LA-CL) monofilaments that provide subdermal support or filling, confer elasticity, and prolong thread stability when implanted $[26,28]$. The double needle threads are convergent bidirectional barbs and are available in $12-$ or $23-\mathrm{cm}$ versions with 9 - or $15-\mathrm{cm} 24 \mathrm{G}$ straight needles at both 
thread extremities $[20,28]$. The subdermal suspension threads lift the tissues by connecting to the dermis retinacula cutis system, the SMAS, and the downward muscular bands [20]. Fibrosis along the thread length may promote neocollagenesis that naturally repositions treated tissues and leads to tissue toning [20]. Immediately after implantation, our patients experienced a tissue-lifting effect because of the mechanical actions of the thread and its bidirectional barbs hooking onto the tissues and locking into position.

The tissue areas containing Definisse ${ }^{\mathrm{TM}}$ double needle threads undergo neocollagenesis and elastogenesis, as evidenced by mast cell migration, uniform fibrous encapsulation of the threads, and dermal thickening of the adjacent tissues [23]. Following implantation, threads can induce neocollagenesis, elastogenesis, hyaluronic acid production, and angiogenesis for up to 15 months before total reabsorption occurs, thus providing up to 36 months of progressive tissue lifting and revitalization [28].

Our study was limited by its small sample size and dropout rate of $7.4 \%$ due to loss to follow-up. Therefore, we recommend conducting larger trials in the future with a control group, as well as histological studies after absorbable thread implantation to characterize the biostimulatory and biomechanical effects culminating in tissue volumization.

\section{CONCLUSION}

Absorbable barbed thread implantation results in less long-lasting visible lifting effects than using non-absorbable threads, since reabsorption occurs from 6 months post-procedure onwards, but it is a safe and effective treatment for facial rejuvenation. We found that long threads $(23 \mathrm{~cm})$ had a slightly superior facelifting effect compared to short threads $(12 \mathrm{~cm})$, suggesting a benefit of additional barbs in tissue suspension and biostimulation.

\section{ACKNOWLEDGEMENTS}

This research project was supported by Faculty of Medicine Siriraj Hospital, Mahidol University. The authors wish to thank Surachet Sirisuthivoranunt, Phonsuk Yamlexnoi, and Chutikan Kiatphansodsai for their assistance in recruiting subjects and managing the database.

Disclosures. Rungsima Wanitphakdeedecha, Chadakan Yan, Janice Natasha C. Ng, and Salvatore Fundarò have nothing to disclose.

Compliance with Ethics Guidelines. This study was approved by the ethics committee of the Siriraj Institutional Review Board. Written informed consent was obtained for the publication and use of all patients' images prior to their enrollment in the study. This study was performed in accordance with the Helsinki Declaration of 1964 and its subsequent amendments.

Authorship. All named authors meet the International Committee of Medical Journal Editors (ICMJE) criteria for authorship for this article, take responsibility for the integrity of the work as a whole and have given their approval for this version to be published.

Data Availability. Data sharing is not applicable to this article as no datasets were generated or analyzed during the current study.

Author Contributions. Rungsima Wanitphakdeedecha had full access to all of the data in the study and takes responsibility for the integrity of data and the accuracy of the data analysis. Rungsima Wanitphakdeedecha: study concept and design; analysis and interpretation of data; funding; administrative, technical, or material support; study supervision. Chadakan Yan: Acquisition of data; analysis and interpretation of data drafting of manuscript; statistical analysis. Janice Ng: Drafting of manuscript; analysis and interpretation of data; critical revision of the manuscript for important intellectual content. Salvatore Fundaro: Critical revision of the manuscript for important intellectual content. 
Funding. The Faculty of Medicine Siriraj Hospital, Mahidol University, Bangkok, Thailand have provided funding for all items used in this study. The Menarini Group provided the products used in this clinical study and paid the journal's rapid service fee.

Open Access. This article is licensed under a Creative Commons Attribution-NonCommercial 4.0 International License, which permits any non-commercial use, sharing, adaptation, distribution and reproduction in any medium or format, as long as you give appropriate credit to the original author(s) and the source, provide a link to the Creative Commons licence, and indicate if changes were made. The images or other third party material in this article are included in the article's Creative Commons licence, unless indicated otherwise in a credit line to the material. If material is not included in the article's Creative Commons licence and your intended use is not permitted by statutory regulation or exceeds the permitted use, you will need to obtain permission directly from the copyright holder. To view a copy of this licence, visit http://creativecommons.org/licenses/by$\mathrm{nc} / 4.0 /$.

\section{REFERENCES}

1. Mendelson BC, Wong $\mathrm{CH}$. Changes in the facial skeleton with aging: implications and clinical applications in facial rejuvenation. Aesthetic Plast Surg. 2012;36:753-60.

2. Rohrich RJ, Pessa JE, Ristow B. The youthful cheek and the deep medial fat compartment. Plast Reconstr Surg. 2008;121:2107-12.

3. Flowers RS. Periorbital aesthetic surgery for men: eyelids and related structures. Clin Plastic Surg. 1991;18(4):689-729.

4. Shaw RB Jr, Kahn DM. Aging of the midface bony elements: a three-dimensional computed tomographic study. Plast Reconstr Surg. 2007;119(2): 675-83.

5. Pessa JE. An algorithm of facial aging: verification of Lambros's theory by three-dimensional stereolithography, with reference to the pathogenesis of midfacial aging, scleral show, and the lateral suborbital trough deformity. Plast Reconstr Surg. 2000;106(2):479-90.

6. Wong $\mathrm{CH}$, Mendelson B. Newer understanding of specific anatomic targets in the aging face as applied to injectables: aging changes in the craniofacial skeleton and facial ligaments. Plast Reconstr Surg. 2015;136(5 Suppl):44S-48S.

7. Donath AS, Glasgold RA, Glasgold MJ. Volume loss versus gravity: new concepts in facial aging. Curr Opin Otolaryngol Head Neck Surg. 2007;15:238-43.

8. Le Louarn C, Buthiau D, Buis J. Structural aging: the facial recurve concept. Aesth Plast Surg. 2007;31(3): 213-8.

9. Gosain AK, Klein MH, Sudhakar PV, Prost RW. A volumetric analysis of soft-tissue changes in the aging midface using high-resolution MRI: implications for facial rejuvenation. Plast Reconstr Surg. $2005 ; 115: 1143-52$.

10. Owsley JQ. Elevation of the malar fat pad superficial to the orbicularis oculi muscle for correction of prominent nasolabial folds. Clin Plastic Surg. 1995;22:279-93.

11. Rohrich RJ, Pessa JE. The fat compartments of the face: anatomy and clinical implications for cosmetic surgery. Plast Reconstr Surg. 2007;119: 2219-27.

12. Little JW. Volumetric perceptions in midfacial aging with altered priorities for rejuvenation. Plast Reconstr Surg. 2000;105:252-66.

13. Shaw RB Jr, Katzel EB, Koltz PF, et al. Aging of the mandible and its aesthetic implications. Plast Reconstr Surg. 2010;125(1):332-42.

14. Pecora NG, Baccetti T, McNamara JA Jr. The aging craniofacial complex: a longitudinal cephalometric study from late adolescence to late adulthood. Am J Orthod Dentofacial Orthop. 2008;134(4):496-505.

15. Rohrich RJ, Pessa JE. The retaining system of the face: histologic evaluation of the septal boundaries of the subcutaneous fat compartments. Plast Reconstr Surg. 2008;121(5):1804-9.

16. Mack WP. Complications in periocular rejuvenation. Facial Plast Surg Clin North Am. 2010;18(3): 435-56.

17. Ogilvie MP, Few JW Jr, Tomur SS, et al. Rejuvenating the face: an analysis of 100 absorbable suture suspension patients. Aesthet Surg J. 2018;38(6): 654-63.

18. Hau K. Malar Reshaping (MR) technique for Anterior Projection in Asian faces using bidirectional 
barb thread suspension surgery. 24th World Congress of Dermatology Milan 2019. https://www. wcd2019milan-dl.org/abstract-book/start.html. 2019. Accessed 10 June 2019.

19. Suh DH, Jang HW, Lee SJ, et al. Outcomes of polydioxanone knotless thread lifting for facial rejuvenation. Dermatol Surg. 2015;41(6):720-5.

20. Savoia A, Accardo C, Vannini F, et al. Outcomes in thread lift for facial rejuvenation: a study performed with happy liftTM revitalizing. Dermatol Ther (Heidelb). 2014;4(1):103-14.

21. Park JH, Lee BK, Park SH, et al. Preparation of biodegradable and elastic poly( $\varepsilon$-caprolactone-colactide) copolymers and evaluation as a localized and sustained drug delivery carrier. Int J Mol Sci. 2017;18(3):671.

22. Tavares JP, Oliveira CACP, Torres RP, Bahmad F Jr. Facial thread lifting with suture suspension. Braz J Otorhinolaryngol. 2017;83(6):712-9.

23. Wong V. Efficacy of bidirectional barbed polycaprolactone threads in repositioning of soft tissue in the neck. J Clin Exp Dermatol Res. 2020;8(1):19S.

24. Hau K. Early surgical adverse events and incidence rates in bidirectional barb suspension thread surgery. Dermatol Res. 2019;1(1):1-3.

25. Sundaram $H$. The new science of threads - an evidence-based paradigm for physiological tissue mobilisation and reshaping. PRIME J. http://www. prime-journal.com/the-new-science-of-threads-anevidence-based-paradigm-for-physiological-tissuemobilisation-and-reshaping/. 2019. Accessed 26 June 2021.

26. Santorelli A, Cerullo F, Cirillo P, Cavallini M, Avvedimento S. Mid-face reshaping using threads with bidirectional convergent barbs: A retrospective study. J Cosmet Dermatol. 2021;20(6):1591-1597.

27. Alexiades-Armenakas M, Rosenberg D, Renton B, et al. Blinded, randomized, quantitative grading comparison of minimally invasive, fractional radiofrequency and surgical face-lift to treat skin laxity. Arch Dermatol. 2010;146:396-405.

28. Wong V. The science of absorbable poly (L-LactideCo- $\varepsilon$-Caprolactone) threads for soft tissue repositioning of the face: an evidence-based evaluation of their physical properties and clinical application. Clin Cosmet Invest Dermatol. 2021;14:45.

29. Sulamanidze M. Evaluation of a novel technique for wound closure using a barbed suture. Plast Reconstr Surg. 2007;120(1):349-50.

30. Ruff G. Technique and uses for absorbable barbed sutures. Aesthet Surg J. 2006;26(5):620-8.

31. Kapicioğlu Y, Gül M, Saraç G, Yiğitcan B, Gözükara $\mathrm{H}$. Comparison of antiaging effects on rat skin of cog thread and poly-L-lactic acid thread. Dermatol Surg. 2019;45(3):438-45.

32. Dattilo PP Jr, King MW, Cassill NL, et al. Medical textiles: application of an absorbable barbed bi-directional surgical suture. JTATM. 2002;2(2):1-5.

33. Consiglio F, Pizzamiglio R, Parodi PC, et al. Suture with resorbable cones: histology and physico-mechanical features. Aesthet Surg J. 2016;36(3): NP122-7.

34. Wong V, Rafiq N, Kalyan R, et al. Hanging by a thread: choosing the right thread for the right patient. J Dermat Cosmetol. 2017;1(4):86-8. 